\title{
A New Browser for the Visualization of Equation of State Data
}

\author{
G.J. Streletz \\ L.H. MacFarland
}

This paper was prepared for submittal to the

American Physical Society

11th Topical Conference on Shock Compression of Condensed Matter

Snowbird, UT

June 27-July 2, 1999

June 25, 1999

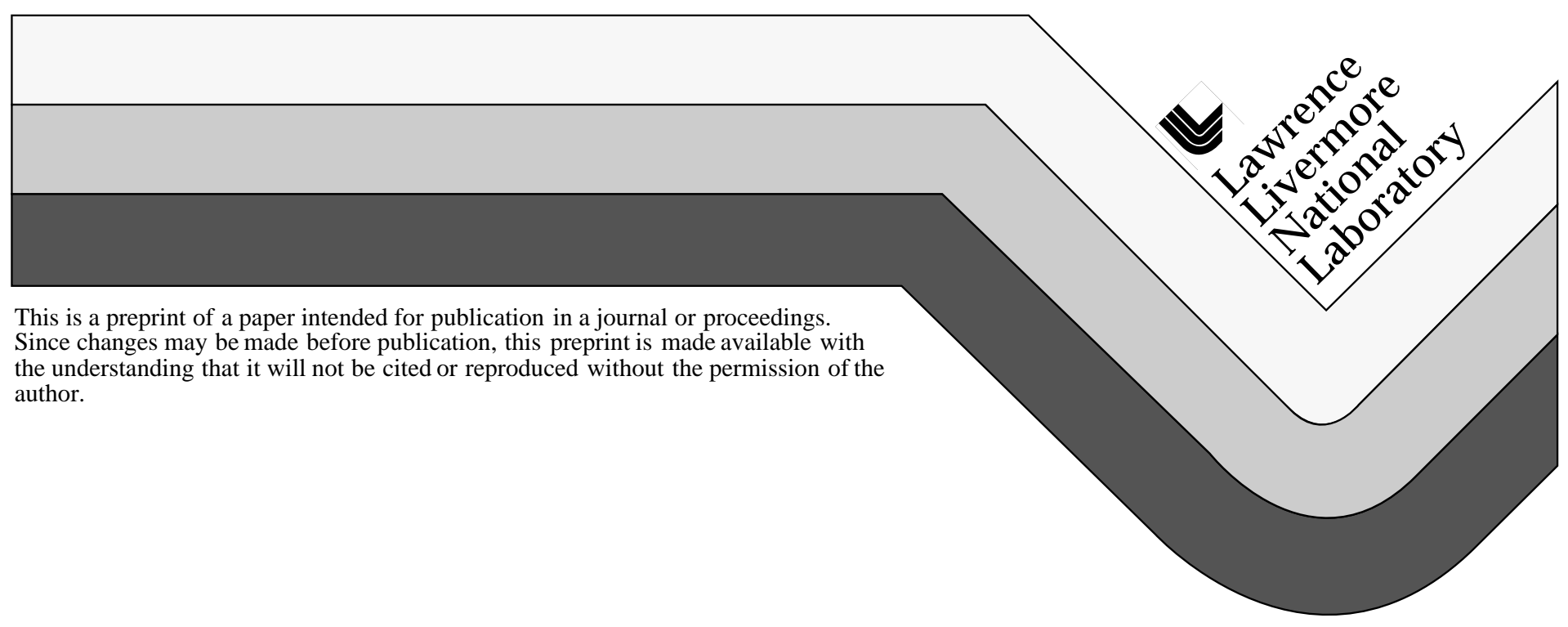




\section{DISCLAIMER}

This document was prepared as an account of work sponsored by an agency of the United States Government. Neither the United States Government nor the University of California nor any of their employees, makes any warranty, express or implied, or assumes any legal liability or responsibility for the accuracy, completeness, or usefulness of any information, apparatus, product, or process

disclosed, or represents that its use would not infringe privately owned rights. Reference herein to any specific commercial product, process, or service by trade name, trademark, manufacturer, or otherwise, does not necessarily constitute or imply its endorsement, recommendation, or favoring by the United States Government or the University of California. The views and opinions of authors expressed herein do not necessarily state or reflect those of the United States Government or the University of California, and shall not be used for advertising or product endorsement purposes. 


\title{
A NEW BROWSER FOR THE VISUALIZATION OF EQUATION OF STATE DATA
}

\author{
Gregory J. Streletz and Lynn H. MacFarland \\ Lawrence Livermore National Laboratory, University of California, P.O. Box 808, Livermore, CA 94551 USA
}

\begin{abstract}
A prototype equation of state (EOS) browser application has been developed at LLNL. This browser provides an interactive, graphical user interface that allows EOS data to be analyzed, visualized, and compared with experimental data. The user can view our EOS table data in both tabular and graphical form, can obtain lists of table ranges, and can view material information. In addition, the browser allows the user to utilize the interpolation routines of our EOS package to produce the same interpolated EOS data that would be passed to a simulation code, and to analyze this data in many different ways. Interpolated data can be obtained through use of a query function, and lists of interpolated data over various ranges can be produced. Analysis functions include the calculation and display of isotherms, isochores, isobars, adiabats, and shock Hugoniots. Moreover, experimental data can be overlaid onto these plots in order to establish confidence in particular EOS tables. It is expected that this browser environment will be a valuable tool for scientists who use large simulation codes that access equation of state data.
\end{abstract}

\section{INTRODUCTION}

Equation of state (EOS) data is an important component of many large-scale simulations of various processes that occur at high energy densities. One approach to providing EOS data to a simulation code is to maintain tabular representations of the equations of state for various materials. Simulation codes can obtain the necessary EOS data, then, by accessing the appropriate data table and by performing some type of interpolation to obtain a data value for the precise $(\rho, T)$ point desired. One benefit of the tabular approach to EOS data is that it facilitates the representation of global equations of state over very large ranges of density and temperature.

Obviously, it is desirable for a user of a simulation code to be able to obtain as much information as possible about the EOS data being passed to the code. The accuracy of simulation results can depend critically on the accuracy of the data being used. At LLNL, we have been developing a browser application called EOSView that will allow the users of our tabular EOS data library to obtain a large amount of information about the EOS tables that they are using, and to do so quickly and easily. EOSView provides a graphical user interface, can display data in both tabular and graphical form, and can be used to analyze EOS data in many different ways.

\section{THE LEOS EQUATION OF STATE DATA LIBRARY}

At LLNL, the equation of state group has developed an EOS data library called LEOS ("Livermore Equation of State"). The LEOS data library contains tabular equation of state data for almost 150 materials. The data are generated using a global EOS model called QEOS ("Quotidian Equation of State"). This 
model is based on a modified Thomas-Fermi electron-gas model, and incorporates adjustable parameters that allow fits to experimental data to play a large role in the generation of the LEOS data tables $[1,2]$.

Currently, the LEOS data library provides data for eighteen different functions. All or most of these functions are available for a vast majority of the materials in the data library. The available functions are listed in Table 1. Except for a few univariate functions, the data are given as a function of density and temperature.

TABLE 1. The Functions Currently Available in the LEOS Data Library

\begin{tabular}{|c|c|c|c|}
\hline $\mathrm{Pt}$ & Total pressure & $\mathrm{Kr}$ & $\begin{array}{c}\text { Rosseland } \\
\text { mean opacity }\end{array}$ \\
\hline $\mathrm{Et}$ & Total energy & $\overline{\mathrm{Kp}}$ & $\begin{array}{c}\text { Planck mean } \\
\text { opacity }\end{array}$ \\
\hline $\mathrm{Pc}$ & Cold pressure & Zeff & $\begin{array}{c}\text { Effective } \\
\text { charge }\end{array}$ \\
\hline $\mathrm{Pi}$ & Ionic pressure & $\mathrm{Tm}$ & $\begin{array}{c}\text { Melting } \\
\text { temperature }\end{array}$ \\
\hline $\mathrm{Pe}$ & $\begin{array}{l}\text { Electronic } \\
\text { pressure }\end{array}$ & $\mathrm{Cs}$ & Sound speed \\
\hline $\mathrm{Ec}$ & Cold energy & $\mathrm{P} 2 \mathrm{p}$ & $\begin{array}{l}\text { Two-phase } \\
\text { pressure }\end{array}$ \\
\hline $\mathrm{Ei}$ & Ionic energy & E2p & $\begin{array}{c}\text { Two-phase } \\
\text { energy }\end{array}$ \\
\hline $\mathrm{Ee}$ & $\begin{array}{c}\text { Electronic } \\
\text { energy }\end{array}$ & S2p & $\begin{array}{l}\text { Two-phase } \\
\text { entropy }\end{array}$ \\
\hline $\mathrm{St}$ & Total entropy & Ecp & $\begin{array}{l}\text { Chemical } \\
\text { potential }\end{array}$ \\
\hline
\end{tabular}

The LEOS data library resides entirely in a single binary file with an internal hierarchical structure [3]. This file is a PDB ("Portable Data Base") file that is created using file management routines from the PDBLib library [4]. In general, the top level of the hierarchy contains a list of the materials in the data library, while the level just below contains a list of the available functions for the given material (material information is available at this level as well). Once the desired function is selected, the next level of the hierarchy contains the table data, as well as other information about the given table.

The contents of the LEOS data library are viewable through the use of a utility called PDBView [5]. PDBView provides a UNIX-like command-line interface with which to navigate the hierarchical structure of the data library. This gives the user a direct way to see what is in the library. However, PDBView has several shortcomings. First, the command-line interface is cumbersome and difficult to use. Secondly, PDBView lacks a general scheme for the graphical visualization of the data, and it does not provide functionality to allow the user to analyze the EOS data or to compare the data with experimental data points.

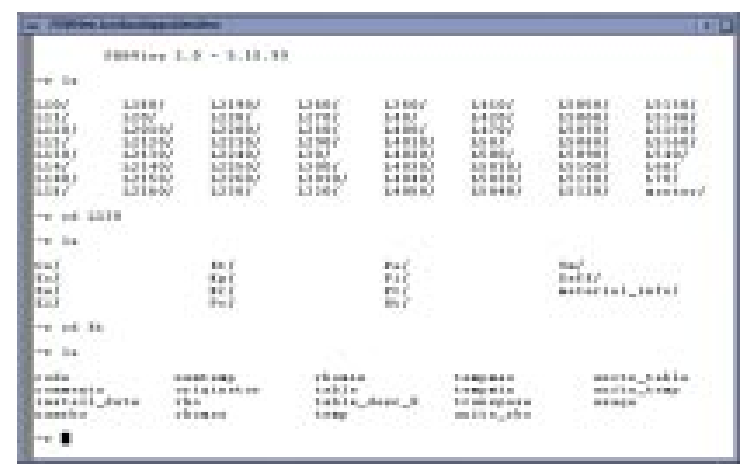

FIGURE 1. The PDBView interface to the LEOS data library.

\section{EOSVIEW: A NEW BROWSER APPLICATION FOR LEOS}

Because of the limitations of PDBView as a data library browser, we have been developing the prototype of a new browser application called EOSView. EOSView provides analysis and graphical visualization capabilities, as well as an easy-to-use graphical user interface. EOSView has already proven to be a valuable tool for the analysis and visualization of data from the LEOS data library. 


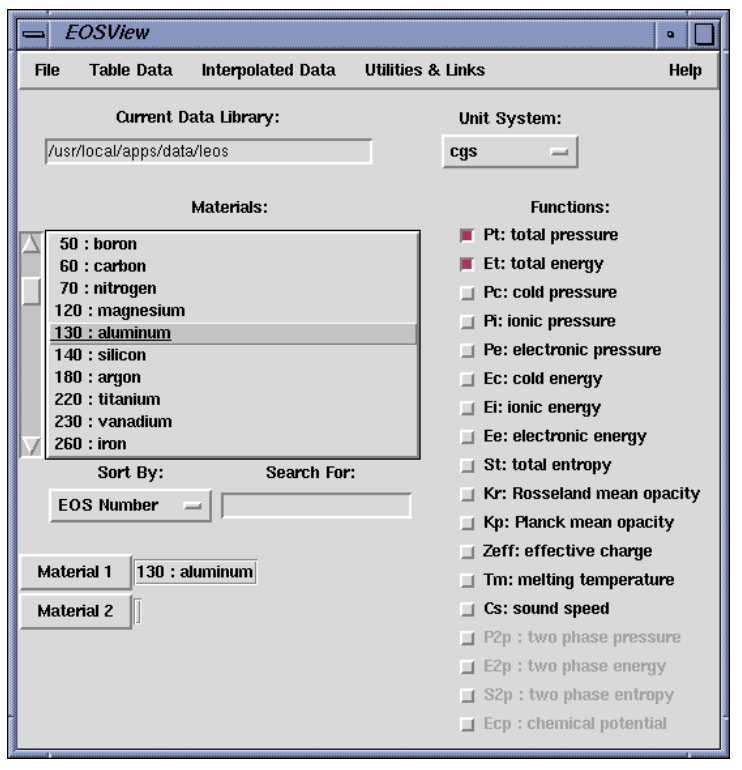

FIGURE 2. The EOSView main window.

The EOSView application uses the Tk GUI toolkit to provide a graphical user interface (GUI) that eliminates the learning curve associated with using a command-line driven interface such as PDBView. Graphics for plotting are provided by the Gnuplot package. The various analysis routines (to calculate adiabats, Hugoniots, etc.) have been coded as $\mathrm{C}$ functions. Moreover, the EOS data are obtained from the LEOS data library by using the same Clanguage access routines and interpolation functions that would be used by a simulation code. This not only facilitated quick prototyping of the EOSView browser, but also serves as a quality assurance feature. Because EOSView uses the same access routines that simulation codes use, a user of the browser can be assured that the data viewed and analyzed there will be the same as the data that will be passed to his or her simulation code.

The "glue" that holds the EOSView application together is provided by the Python scripting language. Python is used to access the Tk GUI widget set; this is made possible by an interface package called Tkinter. Furthermore, Python has proven to be an effective means of creating a single application from disparate building blocks such as $\mathrm{C}$ functions, the Gnuplot program, and various UNIX utilities.

\section{CURRENT EOSVIEW CAPABILITIES}

\section{Accessing Table Data}

EOSView can access essentially all of the data present in the LEOS data library, and can organize and present this information in a way that is convenient for users. For example, a user can create a list of all the materials available in the library, including indications of which of the eighteen functions are available for each of these materials. In addition, information about a given material can be retrieved and displayed with the click of a button. Furthermore, a user can generate a listing of the table ranges for a given material and set of functions.

Of course, EOSView provides the user with ways to view the actual table data itself. After specifying the material and function of interest, a user can display the table data in tabular form, or can obtain a graphical display of either the table grid (in density-temperature space) or of the table values versus density or temperature.

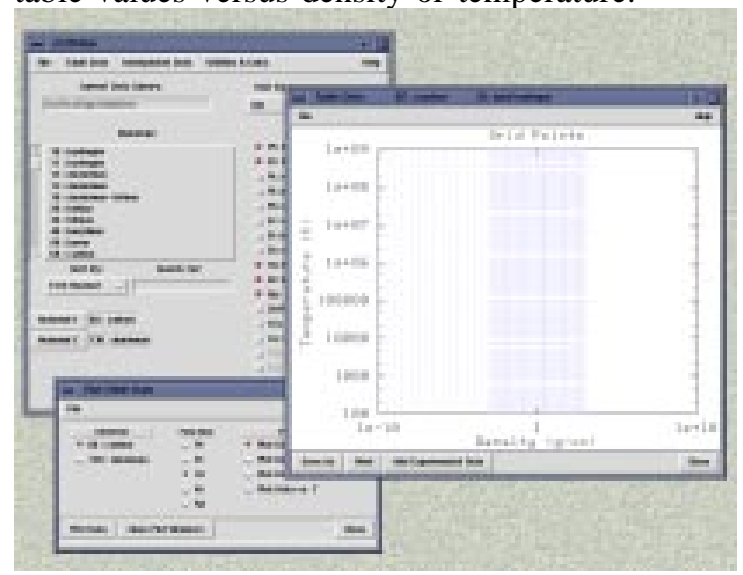

FIGURE 3. Using EOSView to view a graphical depiction of the grid for an EOS table.

\section{Accessing Interpolated Data}

Because the EOSView browser accesses the same interpolation routines that a simulation code using LEOS accesses, the browser is valuable as a means of determining the quality of the data being returned by whichever interpolator (typically a bicubic scheme) has been chosen. There is a query window which allows the user to select a material and function and an arbitrary $(\rho, T)$ point, and to obtain the corresponding function value, as determined by the interpolator. 
A user can also generate a table of interpolated data values for a given material and set of functions; the user selects the desired ranges in density and temperature and the spacing criterion (the number of values, and whether to step linearly or logarithmically).

Furthermore, EOSView provides the user with the ability to analyze interpolated data in several different ways. Functionality of this type includes the calculation and display of isotherms, isochores, isobars, adiabats, and shock Hugoniots. Each of these analyses has an associated GUI window that allows the user to specify all relevant parameters for the analysis. For example, the window for adiabat analysis allows the user to choose the material, the abscissa $(\rho$ or $T)$, the ordinate $(T, \rho$, or one of the previously selected functions), the number of adiabats, the number of points per curve, the initial point or points in $(\rho, T)$ space, whether to compute the adiabat backward or forward from these points (or both), and the ranges in $\rho$ and $T$ within which the analysis is to be confined.

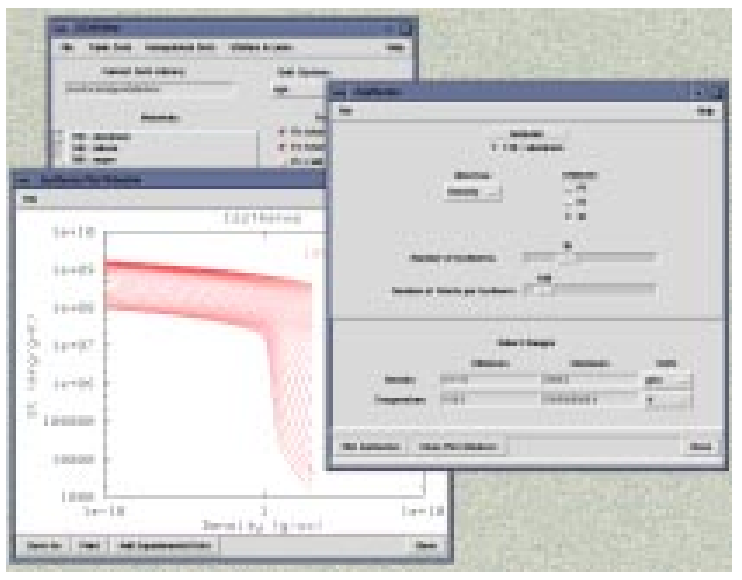

FIGURE 4. Using EOSView to generate and plot entropy isotherms for aluminum.

\section{Other Functionality}

EOSView can overlay experimental data onto any of the plots it creates. The user enters the experimental data directly into a text window, or imports a data file from the local file system. Several separate data files can be imported and displayed in the experimental data text window, and the resulting list of data can be saved in a new file whose name is specified by the user.
The ability of EOSView to compare LEOS data to experimental data is critical for verification and validation purposes.

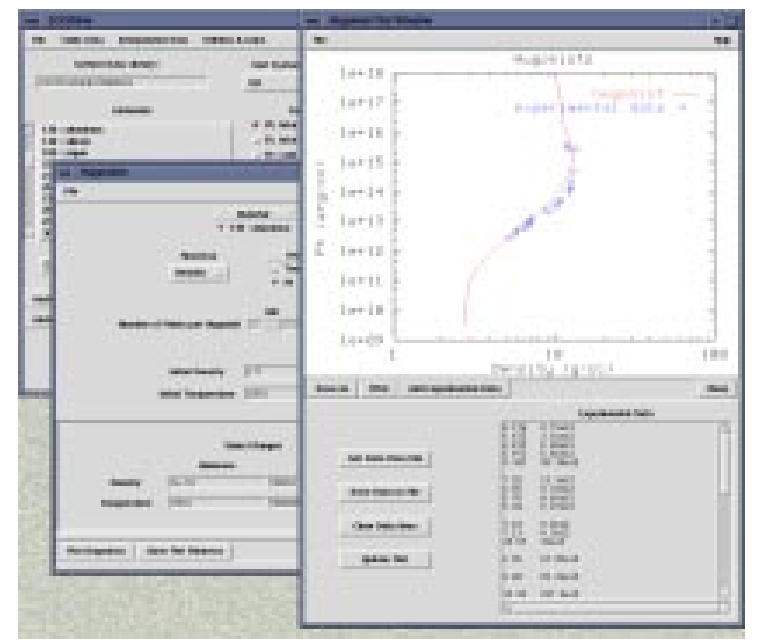

FIGURE 5. Overlaying experimental data onto a Hugoniot curve generated by EOSView.

It is possible to open an arbitrary LEOSformat data library with EOSView. This is useful because special purpose tables are occasionally provided to individual users. Also, EOSView can print tables and plots, or save them to files. Various convenience functions, such as sorting and searching of material lists, are also provided. In addition, there is an interface to PDBView, so that a user can view the contents of the data library directly, if desired.

\section{FUTURE PLANS}

We intend to replace Gnuplot with a much more powerful plotting package in order to provide EOSView with interactive graphics and 3D plotting capabilities. In addition, various quantitative quality metrics will be added to EOSView's functionality. These will involve such things as smoothness, thermodynamic consistency, and thermodynamic stability. Also, we will add the capability to compare EOS tables using contour plots, as well as to handle composite functions such as $\mathrm{E}-\mathrm{TS}+\mathrm{P} / \rho$. Finally, we intend to develop an online library of experimental data. 


\section{ACKNOWLEDGMENTS}

We thank David Young and Ellen Corey for many useful discussions. This work was performed under the auspices of the U.S. Department of Energy by Lawrence Livermore National Laboratory under contract number W7405-ENG-48.
1. More, R., Warren, K. H., Young, D. A., and Zimmerman, G. B., Phys. Fluids 31, 3059-3078 (1988). 2. Young, D. A. and Corey, E. M., J. Appl. Phys. 78, 3748-3755 (1995).

3. Corey, E. M. and Young, D. A., "A New Prototype Equation of State Data Library," in Shock Compression of Condensed Matter - 1997, edited by S. C. Schmidt, et al., AIP Conference Proceedings 429, New York, 1998, pp. 43-46.

4. Brown, S. A., et al., PDBLib User's Manual, LLNL Document M-270 Rev. 3, 1995.

5. Brown, S. A., et al., PDBView User's Manual, LLNL Document UCRL-MA-108968 Rev. 1, 1994.

\section{REFERENCES}

